Journal of Helminthology

cambridge.org/jhl

\section{Research Paper}

Cite this article: Moudgil AD, Moudgil P, Asrani RK, Agnihotri RK (2020). Hydatidosis in slaughtered sheep and goats in India: prevalence, genotypic characterization and pathological studies. Journal of Helminthology 94, e27, 1-5. https://doi.org/10.1017/ S0022149X18001219

Received: 9 October 2018

Accepted: 17 December 2018

\section{Key words:}

fertility; genotyping; histopathology; hydatidosis; small ruminants; viability

Author for correspondence:

A.D. Moudgil

E-mail: moudgil.aman@gmail.com

\title{
Hydatidosis in slaughtered sheep and goats in India: prevalence, genotypic characterization and pathological studies
}

A.D. Moudgil ${ }^{1}$, P. Moudgil ${ }^{2}$, R.K. Asrani ${ }^{3}$ and R.K. Agnihotri ${ }^{1}$

${ }^{1}$ Department of Veterinary Parasitology, DGCN College of Veterinary and Animal Sciences CSK Himachal Pradesh Krishi Vishvavidyalaya Palampur (H.P.), India; ${ }^{2}$ Department of Veterinary Public Health and Epidemiology, College of Veterinary Sciences, LUVAS, Hisar (Haryana) India and ${ }^{3}$ Department of Veterinary Pathology, DGCN COVAS, CSK HPKV Palampur (H.P.) India

\begin{abstract}
The present study determined the prevalence of hydatid cysts in different organs of slaughtered hilly 'Gaddi' breed small ruminants-sheep $(n=230)$ and goats $(n=197)$-in Kangra Valley of the north-western Himalayas, India. Hydatid cysts were found in $12.2 \%(n=28)$ of sheep and $10.7 \%(n=21)$ of goats. Pulmonary echinococcosis was more prevalent in slaughtered sheep and goats (sheep 56.36\%; goats 62.90\%) than hepatic echinococcosis (sheep $43.64 \%$; goats $37.10 \%$ ). Fertility rates were higher in hepatic (81.25\%) and pulmonary cysts of sheep (83.87\%) compared to goats. Molecular identification and genotypic characterization of Echinococcus granulosus isolates were based on mitochondrial cytochrome oxidase 1 gene $(m t \mathrm{CO} 1)$. The genotypic characterization identified the isolated strain to be closely related to the G7 genotype. Histopathological examination revealed a thick coat of granulation tissue, causing fibrosis and inflammatory reaction composed of fibroblasts and mononuclear cells around the cysts. In the liver, hepato-cellular degeneration was prominent at the periphery of the cysts. The present study highlights the molecular confirmation and phylogenetic analysis of E. granulosus isolates with the prevalence of hydatidosis in a naïve host species and in an unexplored region. The findings are of significant medical and veterinary importance regarding development of control measures to check dissemination of hydatidosis.
\end{abstract}

\section{Introduction}

Hydatidosis is a neglected zoonosis. The disease occurs due to infection by larval stages of the tapeworm Echinococcus granulosus. Hydatidosis is a significant public health issue and economic problem in many circumpolar, tropical, and subtropical regions (Daryani et al., 2007). Hydatidosis is endemic in many countries of Asia, South America, the Middle East and Australia (Pednekar et al., 2009). Many species of domestic and wild animals act as intermediate hosts for metacestode stages of E. granulosus (Singh et al., 2012). Sheep are considered the most common and successful intermediate hosts, as they harbour the most fertile cystic stages for the transmission of the infection through dog-sheep life cycles (Soulsby, 1982). Hydatidosis in domestic animals is usually asymptomatic and diagnosed only during postmortem inspection following slaughter at an abattoir.

Various studies have shown the prevalence of hydatidosis in India, particularly in foodproducing animals such as cattle, pigs, buffaloes, sheep and goats (Bhattacharya et al., 2007; Gudewar et al., 2009; Pednekar et al., 2009; Singh et al., 2012). Annual economic losses attributed to hydatidosis in India are approximately USD 212.35 million (Singh et al., 2014). Economic losses as a result of hydatidosis are associated with condemnation of infected liver and lungs (Singh et al., 2012). The consumption of infected lungs and liver causes disease transmission to humans and definitive hosts (Singh et al., 2012). Over 22,721 confirmed sporadic cases of human hydatidosis (17,075 and 5646 cases without and with surgical interventions, respectively) have been reported in India (Singh et al., 2014). Ideal conditions exist for the infection biology of hydatidosis in India; in other words, the country is ideal for the establishment, propagation and dissemination of the disease in both humans and livestock (Pednekar et al., 2009). However, lack of public awareness about the life cycle and transmission of E. granulosus, the absence of proper meat inspection, and improper offal disposal at illegally run abattoirs significantly contribute to the completion of domestic cycles of transmission (Singh et al., 2012).

Until now, ten genotypes of E. granulosus have been reported by molecular genetic analysis of mitochondrial DNA sequences (Bowles et al., 1992; Lavikainen et al., 2003). Generally, E. granulosus genotypes are divided into four subspecies: E. granulosus sensu stricto (G1-G3 genotype), E. equinus (G4), E. ortleppi (G5) and E. canadensis (G6-G10) (Sharma et al., 2013). Among these strains, the G1 genotype is infamous for causing the greatest number 
of human cases of hydatidosis, also known as cystic echinococcosis (Moro and Schantz, 2009). We determined the prevalence of hydatid cysts in various organs of slaughtered hilly 'Gaddi' breed small ruminants of Kangra Valley, India. We also characterized $E$. granulosus isolates that were retrieved by targeting the mitochondrial cytochrome oxidase 1 gene $(m t \mathrm{CO} 1)$.

\section{Materials and methods}

\section{Screening of slaughtered animals and sample collection}

A total of 427 animals (230 sheep and 197 goats) were screened for the presence of hydatid cysts. Lungs and liver of every animal were examined visually, palpated and incised for the detection of hydatid cysts. The infected organs were separated from the carcass, and incised hydatid cysts were analysed at the Department of Veterinary Parasitology, College of Veterinary and Animal Sciences, CSK HPKV Palampur (H.P.) India.

\section{Assessment of fertility and viability of the hydatids}

Hydatid fluid was aspirated with a sterile syringe after washing the cyst with normal saline. The fluid was centrifuged at $5000 \mathrm{rpm}$ for 5 minutes and the pellet was observed at $10 \times$ magnification for the presence of protoscolices. The fertility of the cyst was determined by the presence of protoscolices in the hydatid fluid. The viability of the cysts was assessed by eosin exclusion method, as described earlier (Daryani et al., 2007).

\section{Genomic DNA extraction and PCR amplification}

The cysts were collected carefully and washed with normal saline. The genomic DNA was extracted from the hydatid fluid aspirated from the cysts. The fluid was subjected to centrifugation at $5000 \mathrm{rpm}$ for 5 minutes and the pellet was screened for the presence of protoscolices. The genomic DNA was extracted from sterile and fertile hydatid cysts using a DNeasy Blood and Tissue kit (Qiagen, Hilden, Germany). The extracted DNA was then stored at $-20^{\circ} \mathrm{C}$ until further use. The polymerase chain reaction (PCR) was performed for amplifying DNA sequences encoding mitochondrial cytochrome oxidase 1 (mtCO1) gene. The published primers (Bowles et al., 1992) employed in the present study were JB3 (forward): 5'-TTT TTT GGG CAT CCT GAG GTT TAT- $3^{\prime}$ and JB4.5 (reverse): 5' ${ }^{\prime}$ TAA AGA AAG AAC ATA ATG AAA ATG- $3^{\prime}$. The $25 \mu \mathrm{l}$ PCR reaction mixture contained $12.5 \mu \mathrm{l}$ Master Mix (GoTaq1 Green Mater Mix, Promega, Madison, WI, USA), $2.5 \mu \mathrm{l}$ of each primer (forward and reverse), $5 \mu \mathrm{l}$ genomic DNA and $2.5 \mu \mathrm{l}$ nuclease free water. The following reaction conditions were followed in sequential order: initial denaturation $\left(94^{\circ} \mathrm{C}\right.$ for 5 minutes), denaturation $\left(38\right.$ cycles of $94^{\circ} \mathrm{C}$ for $30 \mathrm{~s}$ ), annealing $\left(38\right.$ cycles of $50^{\circ} \mathrm{C}$ for $45 \mathrm{~s}$ ), extension (38 cycles of $72^{\circ} \mathrm{C}$ for $\left.35 \mathrm{~s}\right)$, and final extension $\left(72^{\circ} \mathrm{C}\right.$ for 10 minutes) (Ehsan et al., 2017). The amplified PCR products/amplicons were separated by electrophoresis on $1.5 \%$ agarose gel and were visualized under UV transilluminator for detection of $446 \mathrm{bp}$ amplicon size.

\section{DNA sequencing and phylogenetic analysis}

The 446 bp amplicons retrieved were custom sequenced (Eurofins Genomics India Pvt. Ltd., Bengaluru). The identification of the sequences and homology was confirmed after comparing the product sequences with the reference sequences (KX874722.1, KX874714.1, HF947595.1, KY499559.1, KT968706.1, KT446001.1, MH010310.1, KC415063.1, JX854035.1, KM100575.1, KX874713.1, HF947555.1, MH010307.1, KT382540.1, HF947553.1, KC660075.1, HM598451.1, HF947574.1, FN646371.1) available in GenBank, by using the Basic Local Alignment Search Tool (Testini et al., 2011). To ensure an open reading frame and to exclude pseudogenes, individual $m t \mathrm{CO} 1$ sequences were deduced into amino acid sequences and were then analysed using MEGA X (Molecular Evolutionary Genetic Analysis) software for phylogenetic analysis (Kumar et al., 2018). The sequences retrieved in the present study were also used for phylogenetic tree construction along with other isolates (exhibiting similitude with the present study isolates), retrieved from GenBank using the Neighbour-Joining method in MEGA X software (Kumar et al., 2018). Bootstrap analyses were conducted using 1000 replicates. Analysis of the estimates of evolutionary divergence between genotype sequences (G1-G10) retrieved from GenBank (Bowles et al., 1992) and the present study was conducted using the maximum composite likelihood model (Tamura et al., 2004).

\section{Histopathological studies}

The samples collected from infected lungs and liver were subjected to histopathological staining as per Luna (1968).

\section{Statistical analysis}

Mean and standard deviation values pertaining to the viability of protoscolices in the fertile cysts were assessed using Microsoft Excel.

\section{Results}

\section{Prevalence studies}

Hydatid cysts were found in $12.2 \%(\mathrm{n}=28)$ sheep and $10.7 \%$ $(\mathrm{n}=21)$ goats. Pulmonary echinococcosis was more prevalent in slaughtered sheep and goats [sheep (56.36\%) and goats $(62.90 \%)$ ] than hepatic infection [sheep (43.64\%) and goats (37.10\%)] (table 1). The cysts were recorded from both visceral and parietal surfaces of the liver. Fertility rates were higher in hepatic $(81.25 \%)$ and pulmonary cysts of sheep $(83.87 \%)$ compared to goats (table 1). Most viable protoscolices were recorded from fertile pulmonary cysts $(68.72 \pm 13.63)$ of sheep (table 1$)$.

\section{Molecular confirmation and phylogenetic distribution analysis}

Amplicons of approximately 446 bp size were retrieved after gel electrophoresis (fig. 1). The custom sequencing analysis of partial $m t \mathrm{CO} 1$ gene of E. granulosus produced sequences of $410 \mathrm{bp}$ for the samples analysed. Echinococcus granulosus isolates retrieved from the lung and liver hydatid cysts of humans of Turkey, accession numbers: KX874714.1, KX874722.1 and KX874721.1, exhibited 100 and 99\%; G7 genotype from cattle in Portugal (HF947574.1) exhibited 99\%; human hydatid cyst isolates from Iran (MH010307.1) exhibited $99 \%$ identity to the isolates retrieved from sheep/goats in the present study from the northwestern Himalayas (fig. 2). The observations based on the maximum likelihood model exhibited more differences in the sequences of various E. granulosus genotypes (G1-G10) with 
Table 1. Fertility of hydatid cysts and viability of protoscolices of fertile cysts recovered from different organs of slaughtered small ruminants.

\begin{tabular}{|c|c|c|c|c|c|c|}
\hline & $\begin{array}{l}\text { Infected } \\
\text { organs } \\
\text { examined }\end{array}$ & $\begin{array}{c}\text { Number of } \\
\text { cysts examined } \\
\mathrm{n} / \mathrm{N}(\%)\end{array}$ & $\begin{array}{l}\text { Number } \\
\text { of sterile } \\
\text { cysts (\%) }\end{array}$ & $\begin{array}{c}\text { Number of } \\
\text { suppurative/ } \\
\text { calcified cysts (\%) }\end{array}$ & $\begin{array}{l}\text { Number } \\
\text { of fertile } \\
\text { cysts (\%) }\end{array}$ & $\begin{array}{l}\text { Viability of protoscoleces } \\
\text { in fertile cysts (Mean } \pm \text { SD) }\end{array}$ \\
\hline \multirow[t]{2}{*}{ Sheep } & Liver & $48 / 110(43.64)$ & $08(16.67)$ & $01(2.08)$ & $39(81.25)$ & $53.37 \pm 7.09$ \\
\hline & Lungs & $62 / 110(56.36)$ & 07 (11.29) & $03(4.84)$ & $52(83.87)$ & $68.72 \pm 13.63$ \\
\hline \multirow[t]{2}{*}{ Goats } & Liver & $23 / 62(37.10)$ & $13(56.52)$ & $01(4.35)$ & 09 (39.13) & $39.61 \pm 8.39$ \\
\hline & Lungs & $39 / 62(62.90)$ & $11(28.21)$ & 04 (10.26) & $24(61.53)$ & $47.97 \pm 10.21$ \\
\hline
\end{tabular}

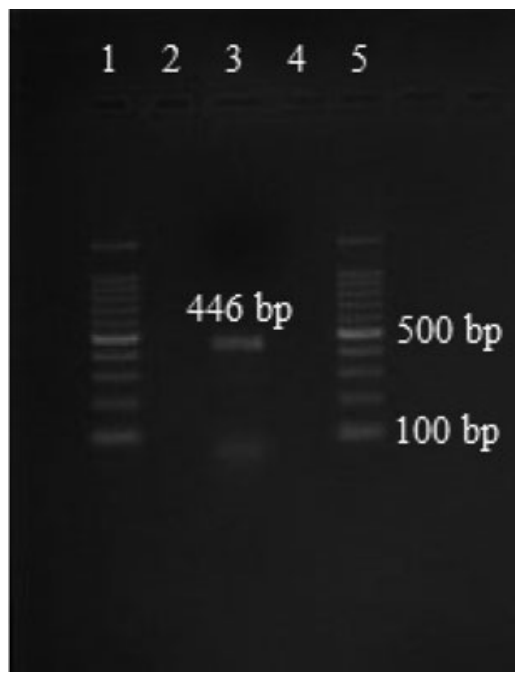

Fig. 1. $P C R$ amplification targeting the $m t C O 1$ gene. $1: 100$ bp plus marker; $2: P C R$ product of sterile hydatid cyst; 3: PCR product of fertile hydatid cyst; 4: PCR product of cysticercus; 5: 100 bp plus marker.

the isolates retrieved in the present study, as the values were extremely high $(>3)$ in pairwise comparison (table 2).

\section{Histopathological observations}

Histopathological examination revealed a thick coat of granulation tissue, causing fibrosis and inflammatory reaction composed of fibroblasts and mononuclear cells around the cysts. In the liver and lungs, large cyst walls were evident, with the presence of inner germinal and outer laminated layers (figs 3 and 4). The hepatocellular degeneration was prominent at the periphery of the cysts. The present study also supports the presence of a channel or space between the ectocyst and pericyst of the cyst wall in the liver (fig. 3). In the lungs, a germinal layer was observed separating from the laminated layer in places, and echinococcal protoscolices were also noticed in certain sections. The cyst wall was surrounded by a zone of inflammatory reaction composed mainly of lymphocytes. Pressure atrophy of adjoining parenchyma rendered alveoli to appear as slit-like structures with a narrow lumen (fig. 4).

\section{Discussion}

An increase in the incidence of hydatidosis in the recent past has been reported from various parts of India (Rao et al., 2012; Nyero et al., 2015). A perusal of the literature indicates a continuous decline in the prevalence of cystic echinococcosis in urban centres in the past few decades (Pednekar et al., 2009). However, past studies mainly screened organized abattoirs slaughtering the livestock from intensively managed large-scale production facilities (Pednekar et al., 2009). On the contrary, the present study highlights the prevalence of hydatidosis in small ruminants of poorly resourced nomadic farmers from unexplored naive areas of the north-western Himalayas.

In rural areas, scavenger dogs contract the infection after consumption of contaminated offal from open-space non-gazetted abattoirs. These infected dogs contaminate the grazing pastures with faeces containing eggs. The slightly higher prevalence of cystic echinococcosis in sheep than goats can be attributed to their feeding habits. Being surface grazers, sheep become potential consumers of the eggs from contaminated pastures (Nyero et al., 2015).

Higher prevalence of pulmonary echinococcosis compared to hepatic infections in sheep and goats can be associated with the immune competence of the host. The compact tissues (such as the liver) resist the development of larger cysts (Torgerson, 2003). The lung parenchyma possesses greater capillary bed and spongy consistency, which supports wider distribution of onchospheres. This provides more space for the development of larger embedded cysts (Beigh et al., 2017). Initial development of the cyst is generally faster (within 10-14 days), but the time required for the formation of fertile cysts with complete structure can take more than 10 months in most of the intermediate host species (Thompson and Lymbery, 1988). We detected a higher rate of fertile and viable cysts in sheep than goats, which is in agreement with the findings of Daryani et al. (2007). The observation of higher rates of fertile cysts in the lungs can also be associated with the greater affinity of G7 genotype for the lungs compared to the liver (Oksanen and Lavikainen, 2015).

Evolution, geographical distribution of parasites and their phylogenetic relationships can significantly contribute to epidemiological studies of parasitic diseases (Lymbery and Thompson, 2012). Hence, identification and geographical distribution of parasites, their etiological roles, and phylogenetic relationships can be established by using techniques based on molecular epidemiological approaches (Archie et al., 2008). Various studies from India have documented distribution of E. granulosus genotype strains [G1, G2, G3 and G5 (cattle, buffalo, sheep and goats) from western India (Bhattacharya et al., 2007; Gudewar et al., 2009; Pednekar et al., 2009), G1 and G3 (cattle, buffalo, sheep, goats and pigs) from northern India (Singh et al., 2012)] in meat-producing animals and in humans (Sharma et al., 2013). The homology of E. granulosus PCR products in the present study is in accordance with Bowles et al. (1992) and Ehsan et al. (2017). The isolates of E. granulosus recovered in the present study are more closely (99\%) related to the G7 genotype strain reported from hydatidosis of cattle in Portugal (Beato et al., 2013). To the best of our knowledge, the present study is the 
Fig. 2. Phylogenetic tree of Echinococcus granulosus isolate retrieved from 'Gaddi' breed sheep and goats in relation to different isolates of intermediate hosts submitted to GenBank based on mitochondrial cytochrome oxidase subunit gene I. The phylogenetic tree was constructed by the Neighbour-Joining method using MEGA $X$ software. The evolutionary distances were computed using the maximum composite likelihood method and are in the units of the number of base substitutions per site.

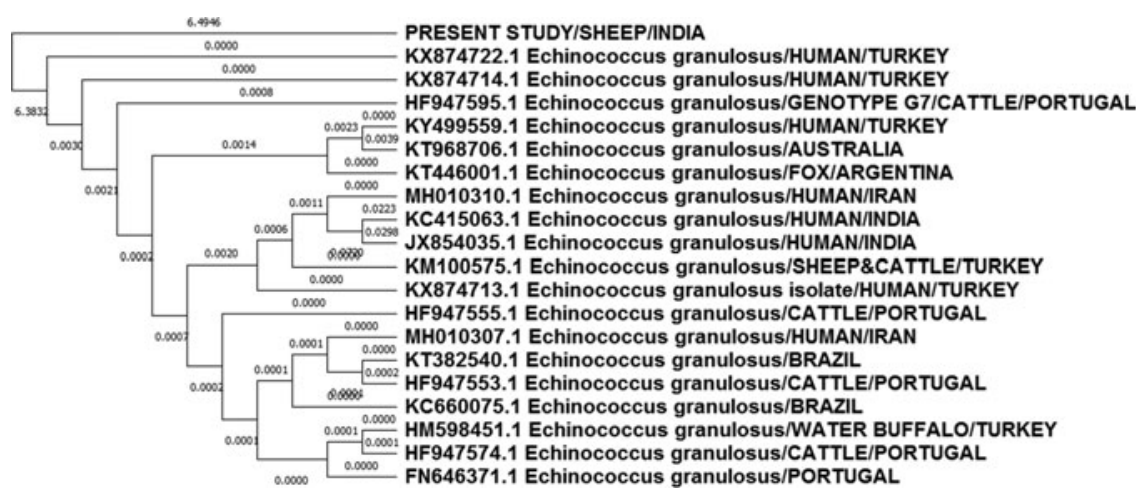

Table 2. Estimates of evolutionary divergence between sequences based on the maximum likelihood model.

\begin{tabular}{|c|c|c|c|c|c|c|c|c|c|c|}
\hline & 1 & 2 & 3 & 4 & 5 & 6 & 7 & 8 & 9 & 10 \\
\hline \multicolumn{11}{|l|}{ U50464.1_Echinococcus_granulosus_G1 } \\
\hline EU151431.1_Echinococcus_canadensis_G8 & 0.13825 & & & & & & & & & \\
\hline AF525457.1_Echinococcus_canadensis_G10 & 0.10061 & 0.05688 & & & & & & & & \\
\hline M84668.1_Echinococcus_multilocularis_G9 & 0.11388 & 0.13427 & 0.11121 & & & & & & & \\
\hline M84667.1_Echinococcus_granulosus_G7 & 0.11184 & 0.04904 & 0.01110 & 0.12232 & & & & & & \\
\hline M84666.1_Echinococcus_granulosus_G6 & 0.10830 & 0.04904 & 0.00831 & 0.11862 & 0.00274 & & & & & \\
\hline M84665.1_Echinococcus_granulosus_G5 & 0.10442 & 0.06410 & 0.04421 & 0.10181 & 0.05383 & 0.05073 & & & & \\
\hline M84664.1_Echinococcus_granulosus_G4 & 0.09716 & 0.11571 & 0.09158 & 0.10757 & 0.10220 & 0.09866 & 0.09888 & & & \\
\hline M84663.1_Echinococcus_granulosus_G3 & 0.00549 & 0.13379 & 0.09801 & 0.11026 & 0.10476 & 0.10125 & 0.10092 & 0.09370 & & \\
\hline M84662.1_Echinococcus_granulosus_G2 & 0.00825 & 0.12935 & 0.09452 & 0.11388 & 0.10125 & 0.09775 & 0.09743 & 0.09026 & 0.00274 & \\
\hline Present study_sheep \& goat_hydatidosis & 3.32717 & 3.49616 & 3.41850 & 3.30853 & 3.31637 & 3.31637 & 3.31270 & 3.35593 & 3.30580 & 3.30784 \\
\hline
\end{tabular}

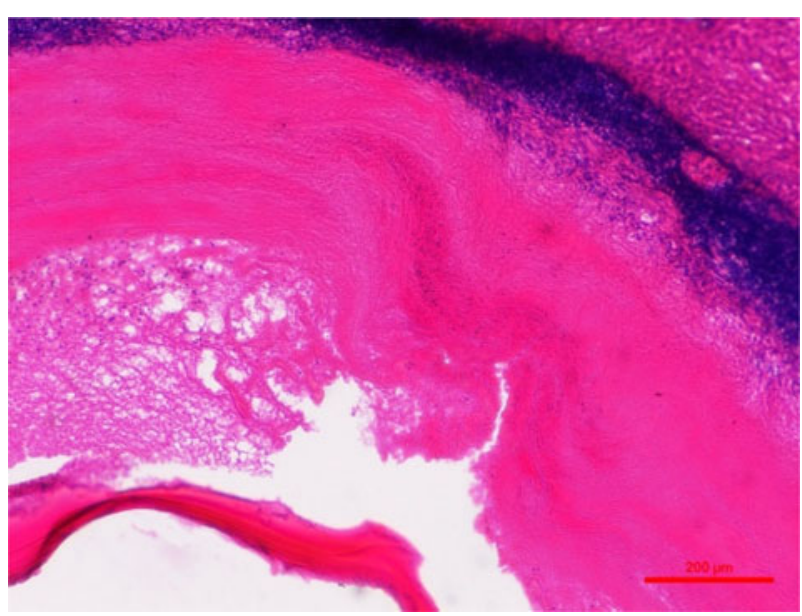

Fig. 3. Liver section with hydatid wall and zone of inflammatory reaction. H\&E $\times 10 X$.

first documented report of the G7 genotype strain of E. granulosus from any intermediate host in India. Previously, the G7 genotype strain has also been reported as a dominant genotypic strain in goats in Spain (Mwambete et al., 2004) and Greece (Varcasia et al., 2007). The finding has raised concern regarding the introduction of newer infective genotypic strains in a new, unexplored

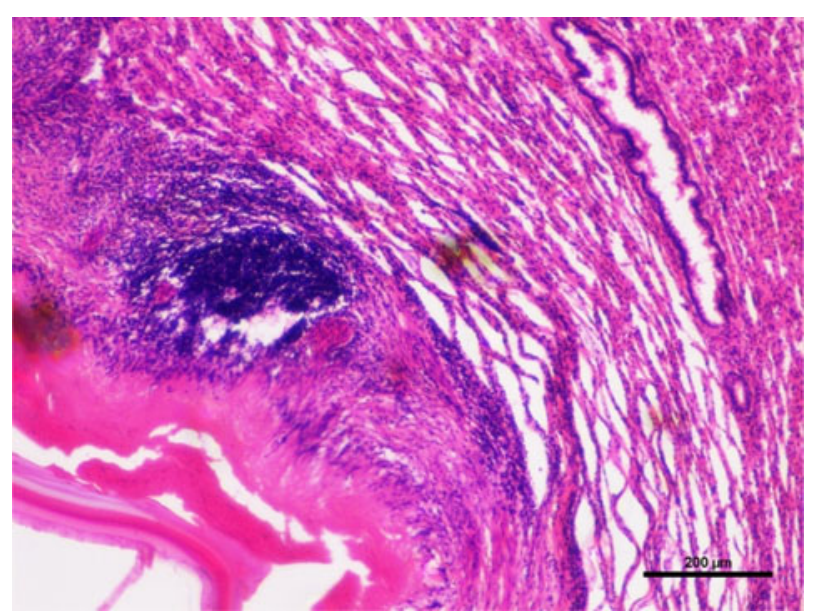

Fig. 4. Lung section with atelectatic alveoli with narrow lumen. $H \& E \times 10 X$.

area. Maximum likelihood model-based analysis of E. granulosus genotype (G1-G10) sequences compared with the present study isolates indicated diverged lineage. Interspecies hybridization can be considered as a possible explanation for this observation, as cross-fertilization occurs less frequently in hermaphrodite organisms (Gudewar et al., 2009). 
The findings pertaining to histopathological studies were in concordance with previous studies (Barnes et al., 2011; Singh et al., 2016). The cysts had adventitial layers of varying thicknesses, protecting them from host immune responses. We also recorded the presence of the germinal membrane, laminated layer, pericyst and ectocyst in the cyst wall of the lungs, as reported by Solcan et al. (2010). The space between the pericyst and ectocyst acts as a channel for the flow of tissue fluids and nutrients. Fibrosis was also evident adjoining the cyst wall. Bronchioles also appeared to be atelectatic and exhibited congestion and haemorrhages in places. Some foci of mineralization were also observed in the adventitial layer. All the observations were in line with the findings of Beigh et al. (2017).

Epidemiological analyses focusing on the frequency, geographical distribution and host range of E. granulosus genetic variants are essential for the implementation of control strategies. The present study highlights the molecular confirmation and phylogenetic analysis of E. granulosus isolates with the prevalence of hydatidosis in a naïve host species and in an unexplored region. The findings are of significant medical and veterinary importance for the development of control measures to check dissemination of hydatidosis.

\section{Author ORCIDs. (D) A.D. Moudgil, 0000-0002-1130-2376.}

Acknowledgements. We thank the Dean of Dr G.C. Negi College of Veterinary and Animal Sciences, Palampur, India, and the Head of the Department of Animal Breeding and Genetics, for providing the facilities to carry out the research work.

Financial support. The present study received no specific grant from any funding agency, commercial or not-for-profit sectors.

\section{Conflict of interest. None.}

Ethical standards. No studies involving laboratory animals or invasive techniques were conducted. The samples were collected from slaughtered animals from local abattoirs.

\section{References}

Archie EA, Luikart G and Ezenwa VO (2008) Infecting epidemiology with genetics: a new frontier in disease ecology. Trends in Ecology and Evolution 24, 21-30.

Barnes TS et al. (2011) Comparative pathology of pulmonary hydatid cysts in macropods and sheep. Journal of Comparative Pathology 144, 113-122.

Beato S et al. (2013) Echinococcus granulosus in Portugal: the first report of the G7 genotype in cattle. Veterinary Parasitology 198, 235-239.

Beigh AB et al. (2017) Gross and histopathological alterations associated with cystic echinococcosis in small ruminants. Journal of Parasitic Diseases 41, 1028-1033.

Bhattacharya D et al. (2007) Genotypic characterisation of Indian cattle, buffalo and sheep isolates of Echinococcus granulosus. Veterinary Parasitology 143, 371-374.

Bowles J, Blair D and McManus DP (1992) Genetic variants within the genus Echinococcus identified by mitochondrial DNA sequencing. Molecular and Biochemical Parasitology 54, 165-173.

Daryani A et al. (2007) The prevalence, intensity and viability of hydatid cysts in slaughtered animals in the Ardabil province of north-west Iran. Journal of Helminthology 81, 13-17.
Ehsan M et al. (2017) Prevalence and genotypic characterization of bovine Echinococcus granulosus isolates by using cytochrome oxidase 1 (CO1) gene in Hyderabad, Pakistan. Veterinary Parasitology 239, 80-85.

Gudewar J et al. (2009) Molecular characterization of Echinococcus granulosus of Indian animal isolates on the basis of nuclear and mitochondrial genotype. Molecular Biology Reports 36, 1381-1385.

Kumar S et al. (2018) MEGA X: Molecular Evolutionary Genetics Analysis across computing platforms. Molecular Biology and Evolution 35, 1547-1549.

Lavikainen A et al. (2003) Molecular genetic characterization of the Fennoscandian cervid strain, a new genotypic group (G10) of Echinococcus granulosus. Parasitology 127, 207-215.

Luna LG (1968) Manual of Histological Staining Methods. Armed Forces Institute of Pathology. New York, NY: McGraw Hill Book Company.

Lymbery AJ and Thompson RCA (2012) The molecular epidemiology of parasite infections: tools and applications. Molecular Biochemical Parasitology 181, 102-116.

Moro P and Schantz PM (2009) Echinococcosis: a review. International Journal of Infectious Diseases, 13, 125-133.

Mwambete KD, Ponce-Gordo F and Cuesta-Bandera C (2004) Genetic identification and host range of the Spanish strains of Echinococcus granulosus. Acta Tropica 91, 87-93.

Nyero D et al. (2015) Prevalence of hydatid cysts in goats and sheep slaughtered in Soroti Municipal Abattoir, Eastern Uganda. African Journal of Parasitology Research 2, 148-151.

Oksanen A and Laivikainen A (2015) Echinococcus canadensis transmission in the North. Veterinary Parasitology 213, 182-186.

Pednekar PR et al. (2009) Molecular and morphological characterisation of Echinococcus from food-producing animals in India. Veterinary Parasitology 165, 58-65.

Rao SS, Mehra B and Narang R (2012) The spectrum of hydatid disease in rural central India: an 11-year experience. Annals of Tropical Medicine and Public Health 5, 225-230.

Sharma M et al. (2013) Molecular characterization of Echinococcus granulosus cysts in North Indian patients: identification of G1, G3, G5 and G6 genotypes. PLOS Neglected Tropical Diseases 7(6), e2262.

Singh BB et al. (2012) Molecular epidemiology of echinococcosis from food producing animals in north India. Veterinary Parasitology 186, 503-506.

Singh BB et al. (2014) Economic losses due to cystic echinococcosis in India: need for urgent action to control the disease. Preventive Veterinary Medicine 113, 1-12.

Singh BB et al. (2016) Histopathological changes associated with E. granulosus echinococcosis in food producing animals in Punjab (India). Journal of Parasitic Diseases 40, 997-1000.

Solcan C et al. (2010) Histological aspects of cystic echinococcosis in goats. Scientica Parasitologica 11, 191-198.

Soulsby EJL (1982) Helminths, Arthropods and Protozoa of Domesticated Animals. 7th Edition. London: Baillere Tindall.

Tamura K, Nei M and Kumar S (2004) Prospects for inferring very large phylogenies by using the neighbour-joining method. Proceedings of the National Academy of Sciences USA 101, 11030-11035.

Testini G et al. (2011) New insights into the morphology, molecular characterization and identification of Baylisascaris transfuga (Ascaridida, Ascarididae). Veterinary Parasitology 175, 97-102.

Thompson RCA and Lymbery AJ (1988) The nature, extent and significance of variation within the genus Echinococcus. Advances in Parasitology 27, 209-258.

Torgerson PR (2003) The economic effects of echinococcosis. Acta Tropica 85, 113-118.

Varcasia A et al. (2007) Preliminary data on diffusion and molecular characterization of cystic echinococcosis in small ruminants in Peloponnesus, Greece. Parasitology Research 131, 547-555. 